\title{
Evaluation of a behavioral treatment for female urinary incontinence
}

\author{
This article was published in the following Dove Press journal: \\ Clinical Interventions in Aging \\ 7 June 2011 \\ Number of times this article has been viewed
}

\section{Marta Santacreu \\ Rocío Fernández- \\ Ballesteros \\ Biological and Health Psychology, Autonomous University of Madrid, Madrid, Spain}

\begin{abstract}
Urinary incontinence is a medical, psychological, social, economic, and hygienic problem. Although it is difficult to state its prevalence, all authors agree that it is related to age and gender. This study aimed to carry out a urinary incontinence behavioral treatment in order to reduce urine leakages in 14 participants recruited from a senior center. The program consists of daily training of the pelvic floor muscles with a weekly control by a supervisor during a 2-month period and follow-up of results 2 months after the last control session. Urinary incontinence episodes were reduced by $75.67 \%$ after program completion. It appears that pelvic floor muscles training, carried out under controlled and constant supervision, significantly reduces urinary leakage. Moreover, maintaining this improvement after treatment depends on the continuation of the exercises as well as on the urinary leakage frequency baseline and the urinary leakage frequency during the last treatment session.
\end{abstract}

Keywords: urinary incontinence, pelvic floor muscle training, quasi-experimental design

\section{Introduction}

Urinary incontinence (UI) represents a very important problem medically, psychologically, socially, economically, and hygienically. ${ }^{1,2}$ People who suffer from UI are more likely to have urinary infections, dermatitis, and suffer from falls. Moreover, UI may increase isolation, despondency, and depression. Economically, UI involves a very high cost. The estimated annual direct average cost of UI per patient in Spain is $€ 262$. The total direct economic impact of UI on the Spanish national healthcare system is $€ 366,687,017 .{ }^{3}$ Everyday expenditures should also be added to this total, such as the increased frequency of clothes washing, the time the family spends taking care of the person suffering from UI, and the costs related to the treatment of emotional and psychological problems.

In Spain, UI is estimated to affect $10 \%$ of women between 25 and 64 years old, approximately $5 \%$ of men between 50 and 65 years, and more than $50 \%$ of people $>65$ years. ${ }^{1,4,5}$ However, these data are variable because of the differences in sample characteristics, the origin of the problem, and the diagnostic criteria used. ${ }^{3,6,7}$

In Spain, most of the UI cases registered are treated with pharmacological and/or surgical therapies or with simple, and usually ineffective, verbal instructions about exercising the pelvic floor muscles without any expert supervision. ${ }^{8}$ These kind of interventions fail to resolve the problem and do not reduce the costs caused by the complaint.

In terms of treatment effectiveness, a great deal of research shows that pelvic floor exercises (Kegel exercises) done in a continuous, constant and controlled manner, are
Correspondence: Marta Santacreu C/lván Pavlov n ${ }^{\circ}$ 6, Campus de Cantoblanco, Universidad Autónoma de Madrid, 28049 Madrid $\mathrm{Tel}+34914975181$

Email marta_santacreu@hotmail.com 
more effective than surgical and pharmacological treatments and have fewer secondary effects. ${ }^{9-12}$ Moreover, these positive results are observed for the 3 main types of UI: stress $U I$ (involuntary leakage during an effort or exertion because of pelvic floor muscle weakness), urge UI (an involuntary loss of urine for no apparent reason after suddenly feeling the need or urge to urinate due to an overactive bladder), and mixed UI (a combination both of the above). ${ }^{7}$

Therefore, the aim of this study was to build a behavioral treatment for feminine UI in order to reduce the involuntary urinary leakage in a group of women volunteers from a senior center. This treatment program was built on Goode et al's research ${ }^{10}$ where a standard behavioral treatment was implemented based on the execution of Kegel exercises in a constant and controlled way. It was also based on research by Subak et $\mathrm{al}^{13}$ which studied urinary leakage episodes by the implementation of a Kegel exercise treatment in a constant and controlled way, but without an exhaustive control of the physical conditions of the urinary tract, as in the studies by Burgio et al and Richter et al., ${ }^{9,14}$ Specifically, the aim of this study was to reduce almost $50 \%$ of the leakage episodes per week by the implementation of such a program and, once the treatment period had finished, performance at least twice a week by participants of the exercises as part of their routine.

\section{Methods}

\section{Participants}

The participants were 14 women volunteers from a senior center. They were asked by their sport instructor from the senior center to participate in the program. To be included in this study, patients had to have had at least 1 incontinent episode the week before starting the program. The sample characteristics are described in Table 1.

\section{Procedure}

This study has a quasi-experimental ("pre-experimental" condition) pre-post with only an experimental group design. ${ }^{16}$ It is necessary to explain the reasons for the limitations of such a design. Originally, 37 women agreed to participate, and were to be randomized to 2 groups: experimental and control in waiting (who would commence treatment 2 months after the first group). In the end, 23 women did not participate in the study, however. The reasons given were: 1) 6 women did not complete the 9-week program; 2) 7 women did not have leakages in the first week of treatment; 3) 3 women were taking care of a family member and did not have time to participate; 4) 4 women did not have time to participate; and 5 ) the remaining 3 women did not give any reason why they did not take part in the research. Therefore, all the participants became part of the experimental group.

\section{Assessment tools}

Two methods to obtain information were used: structured interviews and self-registers. Table 2 summarizes the assessment tools used, including the corresponding references, what these tools measure, and when they are applied. ${ }^{17-20}$

\section{Intervention}

For all subjects, the program consisted of a group information session, an individual assessment session, 8-weekly control

Table I Sample characteristics $N=14$

\begin{tabular}{|c|c|c|c|}
\hline \multicolumn{4}{|l|}{ Age } \\
\hline Mean & \multicolumn{3}{|l|}{67} \\
\hline SD & \multicolumn{3}{|l|}{5.69} \\
\hline Range & \multicolumn{3}{|l|}{$60-80$} \\
\hline \multicolumn{4}{|l|}{ Ul type } \\
\hline Stress & \multicolumn{3}{|l|}{3} \\
\hline Urge & \multicolumn{3}{|l|}{4} \\
\hline Mixed & \multicolumn{3}{|l|}{7} \\
\hline \multicolumn{4}{|c|}{ Sandvik index (UI severity) } \\
\hline Light & \multicolumn{3}{|l|}{1} \\
\hline Moderate & \multicolumn{3}{|l|}{9} \\
\hline Severe & \multicolumn{3}{|l|}{4} \\
\hline \multicolumn{4}{|l|}{ Absorbent pad used } \\
\hline Never & \multicolumn{3}{|l|}{4} \\
\hline In the street & \multicolumn{3}{|l|}{6} \\
\hline Always & \multicolumn{3}{|l|}{4} \\
\hline \multicolumn{4}{|l|}{ Number of children } \\
\hline Mean & \multicolumn{3}{|l|}{2.07} \\
\hline SD & \multicolumn{3}{|l|}{1.44} \\
\hline Range & \multicolumn{3}{|l|}{$0-6$} \\
\hline \multicolumn{4}{|c|}{ Weight of the heaviest child } \\
\hline Mean & \multicolumn{3}{|l|}{3.65} \\
\hline SD & \multicolumn{3}{|l|}{0.76} \\
\hline Range & \multicolumn{3}{|l|}{$2.7-5.3$} \\
\hline \multicolumn{4}{|l|}{ Mode of delivery } \\
\hline Natural & \multicolumn{3}{|l|}{13} \\
\hline Cesarean section & \multicolumn{3}{|l|}{1} \\
\hline Disease & & & \\
\hline Arthritis & 7 & & \\
\hline Hypertension & 2 & & \\
\hline Back problems & 4 & & \\
\hline Parkinson & 1 & & \\
\hline Ul associated drugs & & & \\
\hline Benzodiazepine & 2 & & \\
\hline Antidepressants & 3 & & \\
\hline IU impact & No & Light & Moderate \\
\hline Physical functioning & 12 & 2 & 0 \\
\hline Social activities & 13 & 1 & 0 \\
\hline Emotional state & 8 & 6 & 0 \\
\hline Frustration feelings & 10 & 2 & 2 \\
\hline
\end{tabular}

Note: $*$ The analysis includes: means, standard deviation, and/or frequencies depending on the type of variable. 
sessions, and a follow-up session two months after the treatment. An expert on this topic developed the whole program. The aim of the information session was to introduce the program and explain how it worked. The assessment sessions lasted 40 minutes and involved a structured interview (Table 2). Furthermore, the participants were asked to fill in a self-register to document the time of every void and incontinent episode so as to establish the base line (Table 2). The control sessions took approximately 15 minutes. In these sessions, the supervisor taught the participants how and when to do pelvic muscle exercises at home. The subjects were asked to do these exercises 3 times a day in 3 different positions: lying, sitting, and standing. Every 2 weeks, the supervisor gave the participants new guidelines on the length and the number of contractions and relaxations. Each week, participants were asked to fill out self-registers on leakages and exercises. Moreover, they were praised for bringing back the self-register well completed and all problems or doubts that arose during the previous week were clarified.

After 2 weeks of treatment, when pelvic muscles had become stronger and the exercise regime was set up, participants were encouraged to contract pelvic muscles during activities that commonly resulted in incontinence. For stress UI, they were instructed to contract pelvic muscles when making an effort like sneezing, laughing, or running. The contractions were to be performed at the time of the effort or just before it in order to make the relation between the effort and the pelvic muscles contraction stronger. For urge UI, instead of running to void as soon as they suddenly felt the urge to urinate (which, in turn, raises bladder pressure and increases the chances of leakages), participants were told to sit down (if possible), relax, and contract pelvic muscles repeatedly to reduce the urgency and the detrusor muscle contraction.
They were to try not to void until the urge disappeared, after which they should urinate normally.

Two months after the last control session, the participants were summoned to the follow-up session. In this session, people were asked about their progress on the continuity of exercises, their incontinence episodes, and the frequency of leakage, if appropriate. Finally, participants were asked to fill in a self-register about the frequency of exercises and leakages during the following week.

\section{Results}

Descriptive data analysis was performed on the data collected in the structured interview in order to describe the sample (see Table 1). Correlations were studied to analyze associations between UI and theory-related variables. Repeated measures analyses of variance were performed to analyze treatment effects. Finally, an independent-sample $t$-test was carried out to gauge the differences between the mean leakages, depending on maintaining or stopping the exercises after the treatment. ${ }^{21}$

The application of the treatment program has had positive results, even though the interpretation of these results must be cautious due to the weakness of the experimental design (no control group and a small sample size).

Firstly, some variable associations must be emphasized. On one hand, self-reported UI severity (Sandvik index) correlates $(r=0.761 ; P=0.002)$ with real UI severity (number of leakages in the base line). On the other hand, the more drugs taken, the more self-reported UI severity ( $r=0.643$; $P=0.013)$ and the more real UI severity the participants had $(r=0.716 ; P=0.004){ }^{18}$

For the controlled treatment and the follow-up results, Figure 1 shows that there is an important decrease in the mean

Table 2 Assessment tools

\begin{tabular}{|c|c|c|c|}
\hline Tool & References & What assessments? & Application moment \\
\hline \multirow[t]{5}{*}{ Assessment structured interview } & $\checkmark$ Uebersax et al $^{17}$ & $\checkmark$ UI type & $\checkmark$ At the beginning of the program \\
\hline & $\checkmark$ Klovning $^{18}$ & $\checkmark$ UI severity & \\
\hline & $\checkmark$ Fernández-Ballesteros et al ${ }^{19}$ & $\checkmark$ Associated diseases & \\
\hline & & $\checkmark$ UI impact & \\
\hline & & $\checkmark$ General health & \\
\hline \multirow[t]{2}{*}{ Leakage self-registered } & $\checkmark$ Verdejo 20 & $\checkmark$ Leakage/day & $\checkmark$ Evaluation week \\
\hline & & $\checkmark$ Voiding frequency & $\checkmark$ Every treatment week \\
\hline Exercises self-registered & & $\checkmark$ Exercises control & $\checkmark$ Every treatment week \\
\hline \multirow[t]{2}{*}{ Follow-up structured interview } & & $\begin{array}{l}\checkmark \text { Exercises continuity after } \\
\text { the treatment }\end{array}$ & $\checkmark$ Follow-up week \\
\hline & & $\checkmark$ Exercises frequency & \\
\hline \multirow[t]{2}{*}{ Follow-up self-registered } & & $\checkmark$ Leakage/day & $\checkmark$ Follow-up week \\
\hline & & $\checkmark$ Exercises/day & \\
\hline
\end{tabular}


(Mean values at each point time)

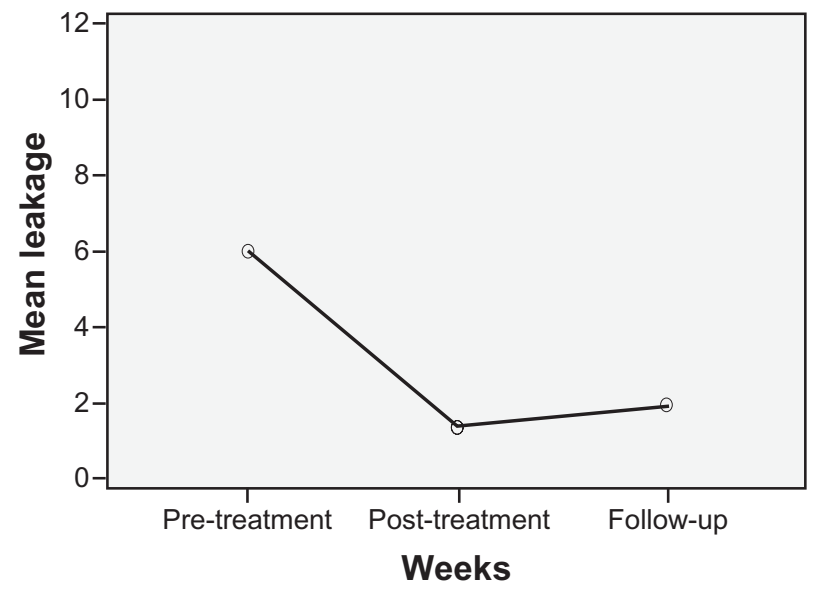

Figure I Development of leakages (mean values at each time point). Note: There are two months between each point time

leakage between the pretreatment week and the post-treatment week and a slight increase in the follow-up week.

In order to see if the decrease in incontinence was significant after the intervention program, a repeated measure analysis of variance was performed. Multivariate contrasts show that the null hypothesis of equal means can be rejected $(F=7.512 ; P=0.008)$ and the sphericity hypothesis cannot be rejected ( $W=0.994 ; P \leq 0.965)$. Therefore, the variances-covariances matrix can be assumed to be spherical. Consequently, an unvaried approximation (sphericity assumed) is used, null hypothesis of equal means can be rejected, and it can be concluded that mean leakages before, after, and at the 2-month follow-up are not the same $(F=8.732 ; P=0.001)$.

In the polynomial contrast test, the null hypothesis of lineal components $(F=11.036 ; P=0.005)$ and quadratic components $(F=6.167 ; P=0.027)$ are rejected. As there are 2 significant components, the one with the higher level is considered to be better fitted, as Figure 1 shows.

The mean leakage in the baseline correlates with the difference between the mean leakage in the pretreatment and post-treatment weeks $(r=0.911 P=0.000)$. This means that the more leakages occurring at the baseline, the greater the decrease. A ground effect exists for the post-treatment week, in which most of the sample had a very low leakage level, hence the pretreatment mean leakage does not correlate with the post-treatment mean leakage ( $r=0.453 ; P=0.104)$. Nevertheless, the baseline mean leakage correlates with mean leakage for the follow-up week $(r=0.539 ; P=0.047)$, which means that the greater the baseline mean leakage, the greater the leakage in the follow-up.
Table 3 shows that women who managed not to experience any urine loss had a significantly lower baseline leakage and leakage in the follow-up week than those who were not able to stop the leakeges.

In the follow-up session, while 7 women reported to have continued doing the pelvic muscle exercises after the treatment, the other 7 reported having stopped them.

We have found that 6 out of 7 women who continued to do the exercises every day maintained the same leakage frequency in the follow-up week as in the last control session (mostly, few or no urine losses). Moreover, of the 7 women who did not continue to do the exercises, 4 suffered a relapse and three improved.

An independent-sample $t$-test was performed to gauge the differences between the mean leakages depending on continuation or halting of the exercises after the treatment. Equal variances have been assumed, as Levene test pointed out, for the 3 variables analyzed. We discovered that the women who continued doing daily exercises after the treatment had a significantly lower baseline leakage than those who ceased the exercises $(F=14.511 ; P=0.002)$. Moreover, they did not experience leakages in the post-treatment week $(F=18.834 ; P=0.001)$, and they had a significantly lower mean leakage in the follow-up week $(F=4.9591 ; P=0.046)$ (Figures 2 and 3).

\section{Discussion}

This study aimed to carry out a UI behavioral treatment in order to reduce the urine leakage by using pelvic floor exercises in volunteer participants from a senior center.

The results show that urge, stress, and mixed UI can be significantly reduced by completing a standard intervention program, consisting of Kegel exercises, as other authors have already proposed. ${ }^{9,14,22,23}$ The women showed a $75.67 \%$ mean reduction, which is approximately the same as shown in data from other studies. ${ }^{14}$ Moreover, it seems that these results continue over time or, at least, it takes time to return to the initial situation, if women continue doing pelvic floor exercises. It would be interesting to carry out more follow-up

Table 3 Independent-sample test

\begin{tabular}{lllllll}
\hline & $\begin{array}{l}\text { Leakage } \\
\text { “post-treatment" }\end{array}$ & $\mathbf{N}$ & $\mathbf{M}$ & SD & $\boldsymbol{F}$ & Sig. \\
\hline Leakage & $\geq 1$ & 6 & 10.67 & 4.50 & 6.44 & 0.026 \\
"pre-treatment" & 0 & 8 & 2.50 & 2.00 & & \\
Leakage & $\geq 1$ & 6 & 4.17 & 5.19 & 6.56 & 0.025 \\
"follow-up" & 0 & 8 & 0.25 & 0.71 & & \\
\hline
\end{tabular}




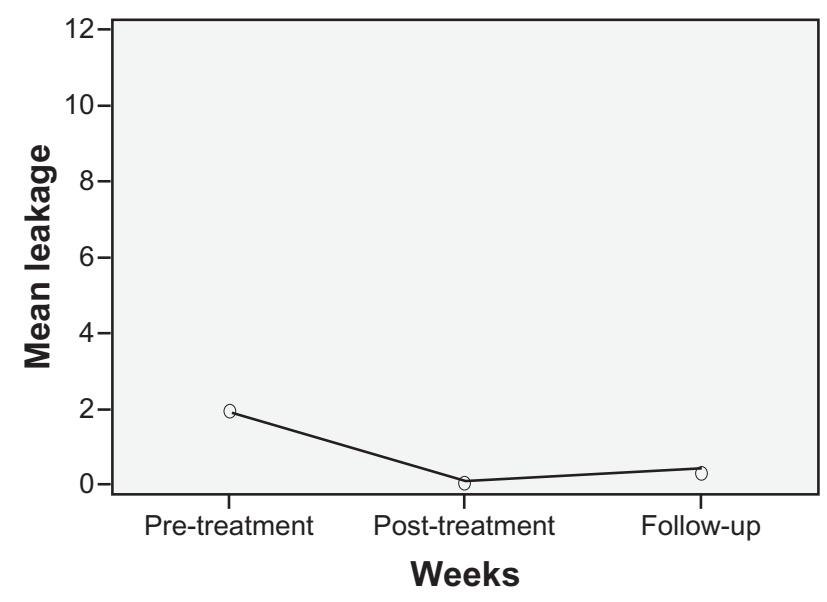

Figure 2 Exercise frequency "daily".

measurements in order to gather more information about how the habit of doing daily pelvic floor exercises (or not) and UI relate to each other.

Moreover, as Subak et al have already pointed out, the physical conditions of the urinary tract do not necessarily have to be exhaustively assessed. ${ }^{13}$ In this study, the incontinence episodes were reduced after doing pelvic floor exercises, even if the potential interfering variables were not taken into account. These results occurred despite the drugs taken (benzodiazepines, antidepressants, or diuretics) or the diseases suffered (diabetes, fecal incontinence), which would normally have excluded these participants from other studies..$^{9,13,14}$ These risk factors were not frequent in this sample, however.

For the risk factors that reduce pelvic floor exercise effectiveness, Richter et al related treatment success to fewer incontinence episodes in the baseline, less

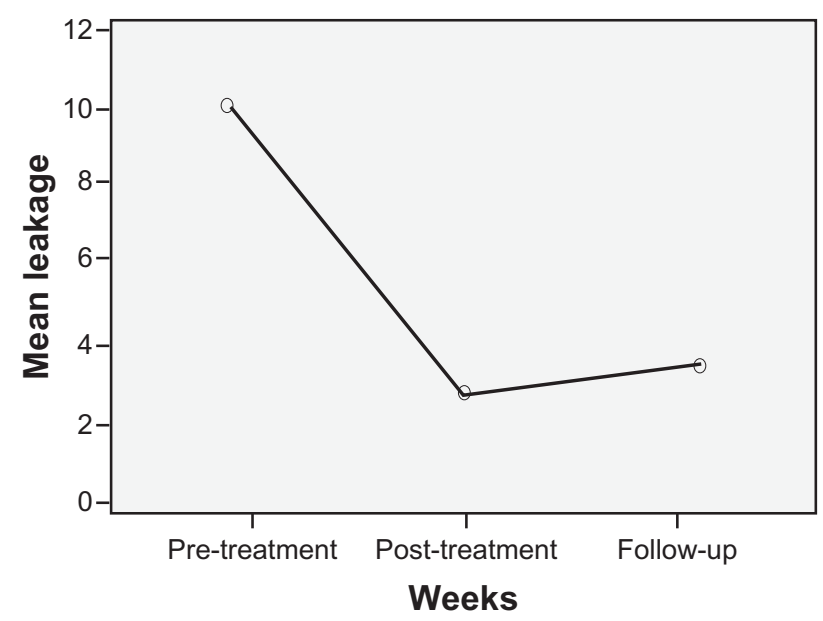

Figure 3 Exercise frequency "not daily". use of absorbents, no UI surgery intervention, and low educational level. In this study, we found a relationship between the number of baseline leakages and those in the follow-up week. ${ }^{9}$ This would mean that, because all the participants had nearly zero leakages by the end of the treatment, the greater the number of urinary leakage episodes at the beginning of the treatment, the greater the difficulty maintaining positive results after treatment. Moreover, relationships between the number of drugs taken and real $(r=0.643 ; P=0.013)$ and self-reported ( $r=0.716 ; P=0.004)$ severity have been found. This aforementioned relationship has already been pointed out by Holroyd-Leduc et al. ${ }^{23}$

Our study confirms the effectiveness of Kegel exercises, although treatment adherence must be taken into account. Every participant knew about Kegel exercises and their benefits, because their doctors had explained these to them, yet they did not perform them. This confirms the importance of having expert supervision (at least, at the beginning) which guarantees the acquisition of the new habit and demonstrates the changes that can occur. On this theme, Burgio et al proposed a research study where the aim was to compare the results between a self-administered Kegel exercise treatment and an identical one that was controlled by an expert. ${ }^{14}$ The study showed that the control group had significantly less incontinence episodes than the selfadministered one.

Getting women into the habit of performing daily pelvic floor exercises was a secondary aim of this study. Half of the sample continued doing daily exercises while the other half continued the exercises just once or twice a week. Women who continued to do daily exercises also had a lower baseline leakage, no leakage at the end of the treatment, and less in the follow-up. This makes the interpretation of data complicated, because of the presence of two variables: number of leakages per week (in base line, last treatment week, and follow-up week) and exercise continuity. According to these results, during the treatment period every participant strengthened their pelvic muscles (observed by the reduction in leakages). However, the strength level was not the same for everyone. While some women completely stopped leakages from the first week, others did not attain this result until the end. Therefore, although the sample had a very low leakage level, some continued having leakages and these participants were the ones who did not continue to do the exercises after the treatment. A possible explanation for this could be that women who continued having incontinence episodes in the 
last treatment week were not motivated enough to continue doing the exercises after the treatment, even though they had experienced a leakage reduction. According to this result, the duration of the treatment (the time of controlled administration) should depend on the UI severity, and expert control should not be removed until the person had a fixed regime and had obtained consolidated results.

In future studies, we propose analyzing the success of the behavioral treatment depending on the UI severity, and controlling the length and frequency of the control and the intensity of the treatment (number of exercises per day), as these are potentially interesting variables.

In spite of the design weakness, the method and results are in accordance with previous studies. ${ }^{14}$ Enhancing this type of treatment is very important because it is effective, has no side effects, and is not intrusive. In fact, in our study, the whole sample reduced their incontinence episodes, regardless of the UI type, the UI severity, and their health characteristics.

In summary, UI is a problem with bio-psychosocial consequences, which can be eliminated or reduced by performing Kegel exercises, even without having an exhaustive control of urinary tract variables. Expert supervision guarantees the efficacy of the treatment in the short and long term.

\section{Conclusion}

- Adherence to the behavioral UI treatment reduces leakage episodes without having an exhaustive control of urinary tract variables.

- In order to get treatment adherence, it is necessary to have expert supervision which guarantees that the exercises are being performed correctly and frequently.

- It is important to continue studying potentially influential variables that increase or reduce UI treatment - not only the variables of the individual but also the treatment variables.

Therefore, this study, in a modest way, contributes to UI treatment and aims to enhance the importance of transmitting real information about UI, such as the fact that UI is a problem that is not inherent to age, ${ }^{24}$ that it can be dealt with by behavioral treatments, and that absorbents are only palliative methods which, far from solving the problem, increase the likelihood of leakages. ${ }^{25}$

\section{Disclosure}

The authors declare no conflicts of interest.

\section{References}

1. Resel Estévez L. Incontinencia Urinaria. Madrid: Clínicas urológicas de la Universidad Complutense de Madrid, Servicio de Publicaciones; 1993:1.

2. Ouslander JG. Causes, assessment and treatment of incontinence in the elderly. Urology. 1990;36:25-35.

3. Irwin DE, Mungapen L, Milsom I, Kopp Z, Reeves P, Kelleher C. The economic impact of overactive bladder syndrome in six Western countries. BJU International. 2008;103:202-209.

4. Martínez-Agulló E, Ruiz JL, Gómez L, et al. Prevalencia de incontinencia urinaria y vejiga hiperactiva en la población española: resultados del estudio EPICC. Actas Urol Esp. 2009;33:159-166.

5. Nieto E, Camacho J, Dávila V, et al. Epidemiology and impact of urinary incontinence in women between 40 and 65 in a health area of Madrid. Atención Primaria. 2003;32:410-414.

6. Thom D. Variation in estimates of urinary incontinence prevalence in the community: effects of differences in definition, population characteristics, and study type. J Am Geriatr Soc. 1998;46:473-480.

7. Coyne KS, Sexton CC, Irwin DE, Kopp ZS, Kelleher CJ, Milsom I. The impact of overactive bladder, incontinence and other lower urinary tract symptoms on quality of life, work productivity, sexuality and emotional well-being in men and women: results from the EPIC study. BJU International. 2008;101:1388-1395.

8. Juarranz M, Terrón R, Roca M, Soriano T, Villamor M, Calvo MJ. Tratamiento de la incontinencia urinaria. Atención Primaria. 2002;30: 323-332.

9. Richter HE, Burgio KL, Chai TC, et al. Predictors of outcomes in the treatment of urge urinary incontinence in women. Int Urogynecol J Pelvic Floor Dysfunct. 2009 Jan 30. [Epub ahead of print].

10. Goode PS, Burgio KL, Locher JL, et al. Effect of behavioral training with or without pelvic floor electrical stimulation on stress incontinence in women. A randomized controlled trial. JAMA. 2003;290: 345-352.

11. Liao Y, Dougherty M, Lioub Y, Tseng Y. Pelvic floor muscle training effect on urinary incontinence knowledge, attitudes, and severity: an experimental study. Int J Nurs Stud. 2006;43:29-37.

12. James R. Balmforth JR, Mantle J, Bidmead J, Cardozo L. A prospective observational trial of pelvic floor muscle training for female stress urinary incontinence. BJU International. 2006;98:811-817.

13. Subak LL, Quesenberry CP, Posner SF, Cattolica E, Soghikian K. The effect of behavioral therapy on urinary incontinence: a randomized controlled trial. Obstet Gynecol. 2002;100:72-78.

14. Burgio KL, Goode PS, Richter HE, Locher JL, Roth1 DL. Global ratings of patient satisfaction and perceptions of improvement with treatment for urinary incontinence: validation of three global patient ratings. Neurourol Urodyn. 2006;25:411-417.

15. Richter HE, Burgio KL, Goode PS, et al; Pelvic Floor Disorders Network. Non-surgical management of stress urinary incontinence: ambulatory treatments for leakage associated with stress (ATLAS) trial. Clin Trials. 2007;4:92-101.

16. Montero I, León OG. A guide for naming research studies in Psychology. Int J Clin Health Psychol. 2007;7:847-862.

17. Uebersax JS, Wyman JF, Shumaker SA, McClish DK, Fantl JA. Short forms to assess life quality and symptom distress for urinary incontinence in women: the Incontinence Impact Questionnaire and the Urogenital Distress Inventory. Neurourol Urodyn. 1995;14:131-139.

18. Klovning A, Avery K, Sandvik H, Hunskaar S. Comparison of two questionnaires for assessing the severity of urinary incontinence: the ICIQ-UI SF versus the incontinence severity index. Neurourol Urodyn. 2009;28:411-415.

19. Fernández-Ballesteros R, Diez Nicolas J, Zamarrón L, et al. Estudio longitudinal sobre envejecimiento activo. Informe de investigación. Madrid: UAM-IMSERSO; 2007.

20. Verdejo C. Incontinencia Urinaria. In: Ribera JM, Cruz AJ, editors. Geriatría en Atención Primaria. Madrid: Aula Médica; 2002:267-277.

21. Ruiz MA, Pardo A. Análisis de datos con SPSS 13 Base. Madrid: McGraw Hill; 2005. 
22. Kegel AH. Progressive resistance exercise in the functional restoration of the perineal muscles. Am J Obstet Gynecol. 1948;56:238-248.

23. Holroyd-Leduc JM, Straus SE. Management of urinary incontinence in women: scientific review. JAMA. 2004;291:986-995.

24. Pfisterer M, Johnson T II, Jenetzky E, Hauer K, Oster P. Geriatric patients' preferences for treatment of urinary incontinence: a study of hospitalized, cognitively competent adults aged 80 and older. $J \mathrm{Am}$ Geriatr Soc. 2007;55:2016-2022.
25. Tannenbaum C, Drali R, Holroyd-Leduc J, Richard L. Lessons learned: impact of a continence promotion activity for older community-dwelling women. Neurourol Urodyn. 2010;29:540-544.

Clinical Interventions in Aging

\section{Publish your work in this journal}

Clinical Interventions in Aging is an international, peer-reviewed journal focusing on evidence-based reports on the value or lack thereof of treatments intended to prevent or delay the onset of maladaptive correlates of aging in human beings. This journal is indexed on PubMed Central, MedLine, the American Chemical Society's 'Chemical Abstracts

\section{Dovepress}

Service' (CAS), Scopus and the Elsevier Bibliographic databases. The manuscript management system is completely online and includes a very quick and fair peer-review system, which is all easy to use. Visit $\mathrm{http}: / /$ www.dovepress.com/testimonials.php to read real quotes from published authors.

Submit your manuscript here: http://www.dovepress.com/clinical-interventions-in-aging-journal 